\section{Rooting and Acclimatization of Micropropagated Vitis labrusca 'Delaware'}

\author{
Veronica T. Lewandowski \\ Research Laboratories, Rohm and Haas Company, 727 Norristown \\ Road, Spring House, PA 19477
}

Additional index words. grape, tissue culture, in vitro, clonal production, establishment

\begin{abstract}
Routine methods were developed to propagate through tissue culture large numbers of Vitis labrusca L. 'Delaware' cuttings on a 10-week production cycle. A 35fold increase in shoots was achieved in 4 weeks through axillary bud proliferation of rejuvenated cultures using a modified Murashige and Skoog (MS) medium. Additive root-stimulating effects from the auxin combination of NAA at $0.001 \mathrm{mg}^{-1}$ iter $^{-1}$ and IBA at $0.005 \mathrm{mg}^{-}$liter $^{-1}$ in half-strength MS resulted in $>95 \%$ rooting of microcuttings in 10 days. More than $95 \%$ of the rooted plantlets were successfully acclimatized within 14 days using greenhouse flats fitted with humidity domes and containing a fortified soilless growing medium. Leaves from 21-day-old greenhouse plantlets lost $21 \%$ water after 40 min of holding at $40 \%$ relative humidity, compared to $62 \%$ from 9-day-old plantlets and $91 \%$ from 3-day-old plantlets. The combined features reported here enable clonal production of $\approx \mathbf{3 0 0 0}$ 'Delaware' grape plants per month using simplified methods and reduced intervals between sequential stages of development. Chemical names used: $\alpha$ - naphthaleneacetic acid (NAA), 1H-indole-3-butyric acid (IBA).
\end{abstract}

The use of tissue culture for clonal propagation of herbaceous and woody plant species has become a well-established practice in commercial industry. While propagation

Received for publication 11 Sept. 1989. I acknowledge Susan M. Lokey, biometrics statistician of Rohm and Haas Co., for her assistance in statistical analysis and interpretation of the data Mention of a trademark or vendor in this publication does not imply endorsement by Rohm and Haas Co. to the exclusion of other products or vendors that may also be suitable. The cost of publishing this paper was defrayed in part by the payment of page charges. Under postal regulations, this paper therefore must be hereby marked advertisement solely to indicate this fact. by conventional means is sometimes hampered by seedling heterozygosity, space and time considerations, seed and cutting dormancy, and limited yields, aseptic micropropagation offers the advantages of rapid clonal multiplication of pathogen-free or virus-indexed plants on a continuous year-round basis.

In vitro techniques used for the propagation of various species and cultivars of Vitis include organogenesis (Barlass and Skene, 1978; Favre, 1977; Iordan et al., 1981; Rajasekaran and Mullins, 1981) and axillary shoot proliferation (Chee and Pool, 1985; Goussard, 1981; Harris and Stevenson, 1982; Novak and Juvova, 1982; Rosu et al., 1983).
Additional reports have described the rooting of grape microcuttings under aseptic conditions (Chee and Pool, 1982, 1988; Harris and Stevenson, 1982; Li and Eaton, 1984; Novak and Juvova, 1982; Rosu et al., 1983; Zatyko and Molnar, 1985). These latter techniques, in combination with axillary shoot proliferation, have the greatest potential for large-scale clonal propagation of Vitis; however, routine production of large numbers has not yet been described.

A further complication to commercial production has been poor acclimatization and establishment of plantlets in the greenhouse (Swartz and Lindstrom, 1986). Carbon dioxide enrichment in controlled environmental chambers has been used with some success to enhance root and shoot growth of acclimatizing grape plantlets (Faulks and Mudge, 1988; Lakso et al., 1986).

It is the aim of this laboratory to identify novel antifungal compounds against the major diseases of $V$. vinifera in many of the world's wine-producing regions. Vitis labrusca 'Delaware' was selected as an indicator species for $V$. vinifera as it is highly susceptible to grape downy mildew (Plasmopara viticola Berl. \& de Toni) and proliferates in tissue culture with ease. Production methods were developed to propagate through tissue culture extensive clonal material on a weekly year-round basis. Experiments reported here were designed to optimize rooting and acclimatization of $V$. labrusca 'Delaware' and to demonstrate the feasibility of large-scale routine production of Vitis.

Cultures were initiated in early June 1987 from weak, shaded shoots of actively growing field-grown vines according to the collection methods of $\mathrm{Yu}$ and Meredith (1986). Single-node explants comprising an axillary bud and a $15-\mathrm{mm}$ section of stem tissue were surface-disinfested with a 15 -sec immersion in $95 \%$ ethanol, followed by continuous agitation for $20 \mathrm{~min}$ in $0.78 \%$ sodium hypo- 
Table 1. Effect of NAA and IBA on rooting of 'Delaware' grape microcuttings.

\begin{tabular}{llccc}
\hline \hline & \multicolumn{4}{c}{ Mean no. rooted cuttings $^{2}$} \\
\cline { 2 - 5 } $\begin{array}{c}\text { NAA } \\
\left(\mathrm{mg} \cdot \text { liter }^{-1}\right)\end{array}$ & 0 & \multicolumn{4}{c}{ IBA $\left(\mathrm{mg} \cdot\right.$ liter $\left.^{-1}\right)$} \\
\hline 0 & $14.2 \mathrm{e}$ & 0.005 & 0.01 & 0.05 \\
\cline { 2 - 5 } 0.001 & $17.9 \mathrm{bcd}$ & $17.3 \mathrm{~d}$ & $17.7 \mathrm{~cd}$ & $19.1 \mathrm{ab}$ \\
0.005 & $17.9 \mathrm{bcd}$ & $19.6 \mathrm{a}$ & $18.3 \mathrm{abcd}$ & $19.4 \mathrm{a}$ \\
0.01 & $18.6 \mathrm{abcd}$ & $8.9 \mathrm{abc}$ & $19.1 \mathrm{ab}$ & $19.3 \mathrm{a}$ \\
\hline
\end{tabular}

${ }^{2}$ Mean of nine observations (20 microcuttings per observation) using a two-way analysis of variance. Square-root-transformed means were separated by Duncan's multiple range test, $\alpha=0.05$. MSE = $0.024, \mathrm{df}=124, P=0.0001$ (IBA $\times$ NAA interaction).

Table 2. Effect of NAA and IBA on the number of roots per rooted 'Delaware' grape microcutting.

\begin{tabular}{|c|c|c|c|c|}
\hline \multirow{3}{*}{$\begin{array}{c}\text { NAA } \\
\left(\mathrm{mg} \cdot \text { liter }^{-1}\right)\end{array}$} & \multicolumn{4}{|c|}{ Mean no. roots ${ }^{2}$} \\
\hline & \multicolumn{4}{|c|}{ IBA $\left(\mathrm{mg} \cdot\right.$ liter $\left.^{-1}\right)$} \\
\hline & 0 & 0.005 & 0.01 & 0.05 \\
\hline 0 & $2.3 \mathrm{~d}$ & $2.5 \mathrm{~cd}$ & $2.6 \mathrm{bcd}$ & $3.0 \mathrm{ab}$ \\
\hline 0.001 & $2.6 \mathrm{bcd}$ & $3.0 \mathrm{ab}$ & $2.5 \mathrm{~cd}$ & $2.7 \mathrm{bcd}$ \\
\hline 0.005 & $2.5 \mathrm{~cd}$ & $2.7 \mathrm{bcd}$ & $2.7 \mathrm{bcd}$ & $2.6 \mathrm{bcd}$ \\
\hline 0.01 & $2.4 \mathrm{~cd}$ & $2.6 \mathrm{bcd}$ & $2.7 \mathrm{bcd}$ & $3.2 \mathrm{a}$ \\
\hline
\end{tabular}

${ }^{2}$ Mean of nine observations (10 rooted microcuttings per observation) using a one-way analysis of variance. Square-root-transformed means were separated by Duncan's multiple range test, $\alpha=0.05$. MSE $=0.112, \mathrm{df}=1396, P=0.0047$ (IBA $\times$ NAA interaction).

chlorite $[15 \%(\mathrm{v} / \mathrm{v})$ chlorine bleachplus $0.1 \%$ $(\mathrm{v} / \mathrm{v})$ Tween 20] and three 20-min rinses in sterile deionized water. Explants were placed in $25 \times 150-\mathrm{mm}$ culture tubes containing a modified Murashige and Skoog (1962) medium (MS) in which the MS inorganic salt base was supplemented with the following components: myo-inositol (100 mg.liter $\left.{ }^{-1}\right)$, thiamine- $\mathrm{HCl}\left(0.4 \mathrm{mg} \cdot\right.$ liter $\left.^{-1}\right)$, 6-benzylaminopurine (BAP) $\left(1.0 \mathrm{mg} \cdot\right.$ liter $\left.^{-1}\right)$, gibberellic acid (GA) (0.45 mg.liter ${ }^{-1}$ ), sucrose (30 g.liter $\left.{ }^{-1}\right)$, and decreased iron $\left(\mathrm{FeSO}_{4} \cdot 7 \mathrm{H}_{2} \mathrm{O}\right.$ $20.9 \mathrm{mg} \cdot$ liter $^{-1} ; \mathrm{Na} \cdot$ EDTA $2 \mathrm{H}_{2} \mathrm{O}, 28.0$ $\mathrm{mg} \cdot$ liter $\left.^{-1}\right)$. The medium was adjusted to $\mathrm{pH}$ 5.7 with $1 \mathrm{~N} \mathrm{KOH}$ before the addition of 0.6\% Difco Bacto-agar and sterilized by autoclaving for $15 \mathrm{~min}$ at $121 \mathrm{C}$ and $105 \mathrm{~Pa}$. Proliferating shoot-tip cultures were subcultured onto fresh medium at 4-week intervals and maintained in a growth chamber with a 16-h photoperiod $\left(52 \mu \mathrm{mol} \cdot \mathrm{s}^{-1} \cdot \mathrm{m}^{-2}\right)$ of coolwhite fluorescent irradiation and diurnally fluctuating day (26C) and night (20C) temperatures. Photosynthetically active radiation was measured with an LI-185B quantum sensor (LI-COR, Lincoln, Neb.).

For the rooting experiment, $1-$ to $2-\mathrm{cm}$ long microcuttings were trimmed of basal leaves and transferred to $80 \times 100-\mathrm{mm}$ round borosilicate culture vessels (Corning Glass Works, Corning, N. Y.) containing root induction medium. MS inorganic salts, thiamine- $\mathrm{HCl}$, myo-inositol, and sucrose were reduced to half their concentration in the proliferation medium, while the iron concentration was further adjusted to 13.9 $\mathrm{mg} \cdot \operatorname{liter}^{-1}\left(\mathrm{FeSO}_{4} \cdot 7 \mathrm{H}_{2} \mathrm{O}\right)$ and $18.7 \mathrm{mg} \cdot \mathrm{liter}^{-1}$ $\left(\mathrm{Na}_{2} \cdot \mathrm{EDTA} \cdot 2 \mathrm{H}_{2} \mathrm{O}\right)$. The auxins IBA and NAA were added to the basal medium in factorial combinations of $0,0.005,0.01$, and $0.05 \mathrm{mg} \cdot$ liter $^{-1}$ and $0,0.001,0.005$, and $0.01 \mathrm{mg} \cdot$ liter $^{-1}$ respectively. Medium ( $\mathrm{pH}$ 5.7) was solidified with $0.6 \%$ Difco Bactoagar and autoclave as described above.
Rooting cultures were maintained under cool-white fluorescent irradiation (125 $\left.\mu \mathrm{mol} \cdot \mathrm{s}^{-1} \cdot \mathrm{m}^{-2}\right)$ at $27 \mathrm{C}$ for 10 days, at which time data were collected. A factorial arrangement of treatments in a randomized complete block design was used to determine the effect of NAA/IBA combinations on rooting. Mean rooting values were derived from the number of microcuttings that rooted out of 20 in each of three replicates, blocked over three test dates. Additional data were drawn from the above experiment relative to the number of roots initiated per rooted microcutting. Root counts were made from 10 random cuttings per replicate, again with three replicates blocked over three dates.

For greenhouse acclimatization, rooted microcuttings were rinsed of all adhering agar with deionized water and placed in $53 \times 28$ $\times 5-\mathrm{cm}$ flats containing premoistened Metromix 500 with starter nutrient charge (W.R. Grace and Co., Cambridge, Mass.). Flats were covered with clear plastic humidity domes and placed in the greenhouse under polypropylene shadecloth $(51 \%)$ at an average light intensity of $410 \mu \mathrm{mol} \cdot \mathrm{s}^{-1} \cdot \mathrm{m}^{-2}$. Plantlets were maintained in the sealed humidity flats for 1 week at $99 \%$ relative humidity (RH), as measured by a Psychro-Dyne psychrometer (Environmental Tectonics Corp., Southampton, Pa.). Beginning on day 7 , domes with perforations of increasing size were substituted every 2 days until day 14 , when the flats were exposed to ambient RH. Acclimatized plantlets were transplanted to 5.7-cm (0.080 liters) plastic square pots filled with Redi-Earth Peat Lite Mix (W. R. Grace and Co.) and watered with continuous-feed fertilizer $(20 \mathrm{~N}-4.4 \mathrm{P}-16.6 \mathrm{~K})$ at $200 \mathrm{ppm}$ elemental N. Two days after transplanting, light intensity was increased to $800 \mu \mathrm{mol} \cdot \mathrm{s}^{-1} \cdot \mathrm{m}^{-2}$ with the removal of shadecloth, while sodium halide lamps provided a photoperiod extension to $16 \mathrm{~h}$ per day $\left(370 \mu \mathrm{mol} \cdot \mathrm{s}^{-1} \cdot \mathrm{m}^{-2}\right)$.
Percent survival was calculated from an average of 50 rooted cuttings per NAA/IBA rooting treatment. There were three replicates per treatment arranged in a completely randomized factorial design.

To determine whether the composition of growing mixtures had any significant effects on the growth of grape plantlets undergoing acclimatization, in vitro-rooted microcuttings (0.01 NAA/0.05 IBA, mg.liter $\left.{ }^{-1}\right)$, were placed in each of four soilless growing mixtures in the greenhouse: 1) Metromix 500 with starter nutrient charge, 2) Redi-Earth Peat-Lite Mix with starter nutrient charge, 3) 1 sphagnum peat :1 medium-grade horticultural perlite (v/v), and 4) no. 3-grade horticultural vermiculite. Two trials were performed, with height data being recorded after 14 days of humidity acclimatization for 20 random plants per treatment in a completely randomized design.

Percent water loss of grape plantlets was determined as a further indicator of humidity acclimatization according to Brainerd and Fuchigami. (1981) for aseptically cultured apples. Six leaves were collected from rooted plantlets at time of transfer to high-humidity flats and at 3, 6, 9, 12, 15, and 21 days thereafter (also designates age of plantlets). Leaves were weighed immediately following excision; dried abaxial side up for 20, 40, and $60 \mathrm{~min}$ at $40 \% \mathrm{RH}$; reweighed; and finally oven-dried at $60 \mathrm{C}$ for $48 \mathrm{~h}$ to be weighed again. The percent water loss relative to each of the three holding times was calculated as: Percent water loss $=($ fresh weight - weight after holding)/(fresh weight - oven dry weight $) \times 100$.

A two-way analysis of variance for main effects and interactions was performed on data from the in vitro rooting experiments. To stabilize variance and improve symmetry, all data were transformed. Raw count data were transformed to square-root values for analysis, and means were separated using Duncan's multiple range test $(\alpha=0.05)$, where a significant interaction effect was indicated. Remaining data were tested for significance with one-way analyses of variance, using the arcsin transformation on survival percentages and the logarithmic transformation on height values. Duncan's multiple range tests were subsequently used to separate transformed means where appropriate. The untransformed variates are reported.

Following initiation into culture from fieldgrown vines, the cultures experienced a lag period of $\approx 8$ weeks before intensive axillary branching was achieved (Fig. 1). This phase was associated with a gradual rejuvenation of morphological characters and a concomitant reduction in endogenous auxin, as manifested in reduced callus production. Thereafter, a 35-fold increase in the number of shoots was achieved every 4 weeks. A total production cycle of 10 weeks was sufficient to culture 'Delaware' grape plantlets from proliferation (4 weeks), to in vitro rooting (10 days), to acclimatization (2 weeks), and finally to the open bench for growing to a height of $12 \mathrm{~cm}$ (3 weeks). Other researchers 
Table 3. Effect of fortified and nonfortified soilless growing mixtures on growth of micropropagated 'Delaware' grape plantlets during acclimatization.

\begin{tabular}{lc}
\hline \hline Growth medium & Plant ht $(\mathrm{cm})^{2}$ \\
\hline Metromix 500 $^{y}$ & $3.6 \mathrm{a}$ \\
Redi-Earth $^{\mathrm{y}}$ & $3.1 \mathrm{a}$ \\
$\begin{array}{l}\text { 1 Sphagnum peat : } \\
\quad \text { perlite (v/v) }\end{array}$ & $2.4 \mathrm{~b}$ \\
$\begin{array}{l}\text { Vermiculite } \\
\quad \text { (Horticultural grade no. 3) }\end{array}$ & $2.2 \mathrm{~b}$ \\
\hline
\end{tabular}

${ }^{2}$ Mean of two observations (20 plantlets per observation) recorded after 14 days of humidity acclimatization. Logarithmic-transformed means were separated using Duncan's multiple range test, $\alpha$ $=0.05$. MSE $=0.085$, df $=75$.

'Fortified with starter nutrient charge (W.R. Grace).

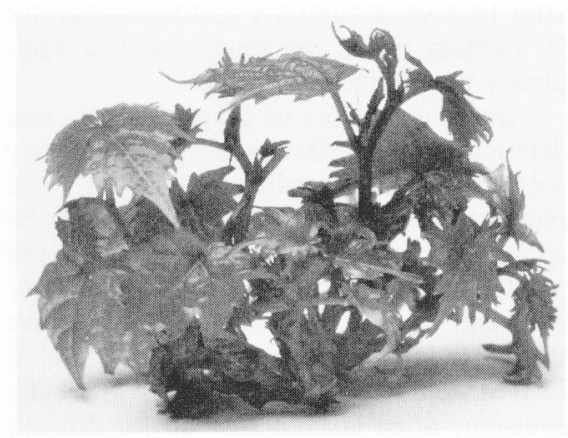

Fig. 1. Axillary bud proliferation in Vitis labusca 'Delaware'.

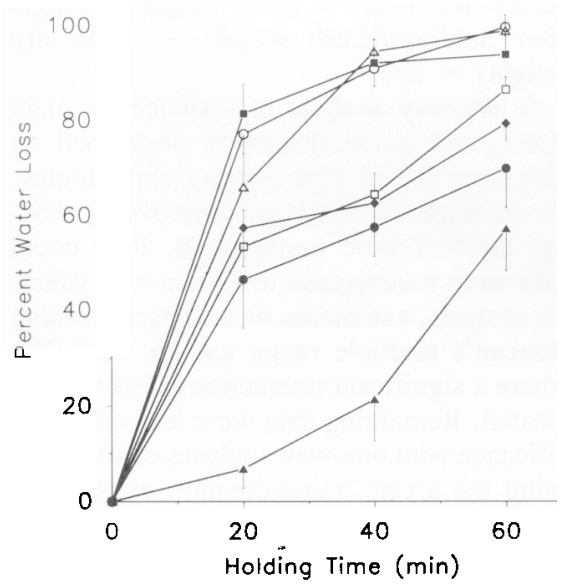

Fig. 2. Water loss from leaves excised from micropropagated 'Delaware' plantlets that were held for various times at $40 \% \mathrm{RH}$. Data are expressed for rooted plantlets at $0(\square), 3(\bigcirc), 6$ $(\Delta), 9(\bullet), 12(\square), 15(\bullet)$, and $21(\boldsymbol{\Delta})$ days of acclimatization, with humidity reduction beginning on day 7 and ending on day 14. Error bars represent the $95 \%$ confidence intervals for the mean $(n=6)$.

have reported production times of no less than 4 months (Barlass and Skene, 1978; Harris and Stevenson, 1982; Rosu et al., 1983).

Various degrees of success in rooting grape microcuttings were achieved previously by using half- or quarter-strength agar-solidified MS medium with various concentrations of IBA or NAA (Chee and Pool, 1982, 1988;
Novak and Juvova, 1982), IBA solution as a pretreatment (Li and Eaton, 1984), MS basal medium with indole-3-acetic acid (IAA) and kinetin, followed by hormone-free MS (Rosu et al., 1983), IAA in a filter paper bridge system (Harris and Stevenson, 1982), and hormone-free Anderson medium (Zatyo and Molnar, 1985). The methods described in this report reliably generate $>95 \%$ rooting within 10 days of culture in half-strength modified MS medium containing combinations of IBA and NAA. Adventitious root initials were first visible on cuttings 5 days after transfer to rooting medium, with no callus production; by day 10 , roots had elongated to $\approx 1 \mathrm{~cm}$, while upper shoot growth was manifested in new leaf expansion and stem elongation. Higher concentrations of each auxin $\left(0.05,0.1,0.5 \mathrm{mg} \cdot \mathrm{liter}^{-1}\right)$ in preliminary work yielded copious callus formation at basal ends of cuttings, while roots at such levels of NAA were thick and fleshy with little secondary branching.

All factorial combinations of NAA and IBA were significantly better at promoting rooting in grape microcuttings than the hormonefree control treatment (Table 1). An interaction of the two auxins indicated a dependence of NAA on the level of IBA. Treatment means corresponded to rooting percentages of 7170 for control cuttings and a range of $86 \%$ to $98 \%$ rooting for treatment combinations.

A significant additive effect at the lowest treatment level (0.001 NAA/0.005 IBA, $\left.\mathrm{mg} \cdot \mathrm{liter}^{-1}\right)$ achieved the same results as the maximum rate (in $\mathrm{mg} \cdot \mathrm{liter}^{-1}$ ) of $0.01 \mathrm{NAA} /$ 0.05 IBA. Goussard (1981) demonstrated additive effects on shoot proliferation of $V$. vinifera 'Chenin Blanc' using a combination of the cytokinins BAP and zeatin riboside; however, an additive effect of auxins, well known to plant propagators for rooting cuttings (Hitchcock and Zimmerman, 1940), has not yet been reported for rooting grape shoot cultures. The significant improvement to rooting observed here with $0.001 \mathrm{NAA} / 0.005$ IBA, mg.liter ${ }^{-1}$, clearly shows an additive effect over the individual treatments applied separately (Tables 1 and 2).

Data expressed as the number of roots per rooted microcutting support the trend established for the rooting experiment. Treatments that yielded the most roots were obtained with the minimum (0.001 NAA/ 0.005 IBA, mg.liter $\left.{ }^{-1}\right)$ and maximum (0.01 NAA/0.05 IBA, mg.liter ${ }^{-1}$ ) factorial combinations (Table 2). Where IBA was absent, increasing concentrations of NAA were ineffective at improving root production over the hormone-free treatment. Addition of NAA at $0.001 \mathrm{mg} \cdot$ liter $^{-1}$ to IBA at $0.005 \mathrm{mg} \cdot$ liter $^{-1}$ resulted in a substantial increase in activity and represented the only treatment that significantly improved rooting over any IBA concentration.

The use of greenhouse flats fitted with humidity domes provided an excellent and rapid method for acclimatization of rooted plantlets with minimal leaf loss and moisture stress. Not only was the need for free-water misting eliminated, but given the very high survival rate of 'Delaware' plantlets, it became evident that $\mathrm{CO}_{2}$ enrichment of the acclimatization environment was not necessary for improved plant growth. Percent survival ranged from $89 \%$ for hormone-free controls to $97 \%$ for treatment combinations. There was no significant difference among treatments, but the highest values were obtained with 0.001 NAA/0.005 IBA and 0.01 NAA/ $0.05 \mathrm{IBA}, \mathrm{mg} \cdot \mathrm{liter}^{-1}$. However, this system does require weaning plantlets off the enriched culture medium using half-strength MS before transplantation into soilless growing medium; previous work in this laboratory demonstrated a substantial reduction in rooting and survival $(42 \%)$ of direct-rooted grape microcuttings treated with $0.1 \%$ IBA on talc (unpublished data).

The inclusion of starter nutrient charge in greenhouse mixes during acclimatization provided an additional boost to plantlet growth and vigor. Analysis of plant height following acclimatization demonstrated that fortified mixes with starter nutrient charge significantly improved plant growth over nonfortified mixes (Table 3 ).

Examination of water loss from excised leaves of grape plantlets held for varying lengths of time at ambient RH effectively monitored humidity acclimatization; however, holding for $40 \mathrm{~min}$ best differentiated acclimatized vs. nonacclimatized leaves (Fig. 2 ). The mean percent water loss decreased with the age of the plantlets, based on the data obtained after $20 \mathrm{~min}$ of holding at $40 \%$ $\mathrm{RH}$. At the 40- and 60-min holding times, means for leaves collected before day 7 (0-, 3-, and 6-day-old plants) were not significantly different from one another, as $\mathrm{RH}$ within sealed flats remained at $98 \%$ to $99 \%$. Means for leaves collected during the subsequent period of humidity reduction with perforated domes (days 7-14) were significantly lower than those for plants at the three previous collection dates, but only significantly different from one another at the 60 min holding time. Fully acclimatized 21-dayold plants obtained from the greenhouse sustained significantly less water loss during all holding times than plantlets at previous collection dates. Relative humidity dropped to $92 \%$ on day 7 following replacement with the minimally perforated domes, and further to $86 \%$ on day 9 and $75 \%$ on day 12 ; complete removal of domes on day 14 yielded an RH equivalent to that in the greenhouse, $66 \%$. In winter, the respective values were $82 \%, 68 \%, 53 \%$, and $46 \%$.

Brainerd and Fuchigami (1981) determined that the rate of water loss of excised aseptically cultured apple leaves was inversely related to the percent stomatal closure. Water loss across the 20-, 40-, and 60min holding times could, therefore, be attributed to slow stomatal response of nonacclimatized leaves, while the reduction of moisture stress over the entire acclimatization process (particularly between days 714) could reflect the more long-term effect of epicuticular was development on leaf surfaces (Grout and Aston, 1977; Sutter and Langhans, 1979). Although acclimatization 
of 'Delaware' plantlets was considered complete by day 14 with the removal of humidify domes. it was evident that additional wax deposition occurred subsequent to that date, as evidenced by the substantial reduction in water loss from greenhouse leaves at day 21 .

While the methods reported here were developed specifically for mass clonal propagation of $V$. labrusca 'Delaware', a few additional Vits genotypes have been micropropagated as well. The Vitis hybrids 'Remaily Seedless' and 'Ravat 51' and the vinifera cultivars Cabernet Sauvignon, Pinot noir, and Chardonnay required slight customizations of medium composition for shoot proliferation, but rooted in vitro and acclimatized to greenhouse conditions with equal success as 'Delaware'. For our purpose, where large quantities of cloned material are necessary for identifying fungistatic compounds with minimal variability, these tissue culture methods are clearly superior to conventional methods of propagation of grapevine. Although some concern has been expressed regarding phenotypic and ecological modifications in field-grown plants as a result of previous rejuvenation in tissue culture (Grenan, 1982), we have not observed any changes in disease susceptibility or gross morphology in 3 years of intensive production. Yearly reisolation from established vineyard stock, in combination with limiting shoot production to axillary bud proliferation, reduce the risk of somaclonal variation.

\section{Literature Cited}

Barlass, M. and K.G.M. Skene. 1978. In vitro propagation of grapevine (Vitis vinifera L.) from fragmented shoot apices. Vitis 17:335-340.

Brainerd, K.E. and L.H. Fuchigami. 1981. Ac- climatization of aseptically cultured apple plants to low relative humidity. J. Amer. Soc. Hort. Sci. 106:515-518.

Chee, R. and R.M. Pool. 1982. The effects of growth substances and photoperiod on the development of shoot apices of Vitis cultured in vitro. Scientia Hort. 16:17-27.

Chee, R. and R.M. Pool. 1985. In vitro propagation of Vitis: The effects of organic substances on shoot multiplication. Vitis 24:106118.

Chee, R. and R.M. Pool. 1988. Sucrose and NAA influence growth of subculture shoots and in vitro production of roots in Vitis. HortScience 23:776.

Favre, J.M. 1977. Premiers resultats concernant l'obtention in vitro de neoformations caulinaires chez la Vigne. Ann. Amelior. Plantes 27:151169.

Faulks, L. and K.W. Mudge. 1988. Optimization of environmental conditions of stage IV micropropagated grapes. HortScience 23:101. (Abstr.)

Goussard, P.G. 1981. Effects of cytokinins on elongation, proliferation and total mass of shoots derived from shoot apices of grapevine cultured in vitro. Vitis 20:228-234.

Grenan, S. 1982. Quelques reflexions a propos de modifications morphogenetiques consecutive a la culture in vitro chez la vigne (Vitis vinifera L.). Ann. Sci. Natl. Bet. 4:135-146.

Grout, B.W. and M.J. Aston. 1977. Transplanting of cauliflower plants regenerated from meristem culture. I. Water loss and water transfer related to changes in leaf wax and to xylem regeneration. Hort. Res. 17: 1-7.

Harris, R.E. and J.H. Stevenson. 1982. In vitro propagation of Vitis. Vitis 21:22-32.

Hitchcock, A.E. and P.W. Zimmerman. 1940. Effects obtained with mixtures of root-inducing and other substances. Contr. Boyce Thompson Inst. 11:143-160.

Iordan, M., A. Brezeanu, and A. Rosu. 1981. The micropropagation of Vitis vinifera L. H. Aspects of morphogenesis in callus culture. Rev.
Roum. Biol.-Biol. Veg. 26:141-150.

Lakso, A. N., B.I. Reisch, J. Mortensen, and M.H. Roberts. 1986. Carbon enrichment for stimulation of growth of in vitro-propagated grapevines after transfer from culture. J. Amer. Soc. Hort. Sci. 111:634-638.

Li, J. and G.W. Eaton. 1984. Growth and rooting of grape shoot apices in vitro. HortScience 19:64-66.

Murashige, T. and F. Skoog. 1962. A revised medium for rapid growth and bioassays with tobacco tissue cultures. Physiol. Plant. 15:473497.

Novak, F.J. and Z. Juvova. 1982. Clonal propagation of grapevine through in vitro axillary bud culture. Scientia Hort. 18:231-240.

Rajasekaran, K. and M.G. Mullins. 1981. Regeneration of grapevines by aseptic methods. Comb. Proc. Intl. Plant Prop. Soc. 31:213-218.

Rosu, A., A. Brezeanu, and M. Iordan. 1983. Micropropagation of Vitis vinifera L.: III. Studies regarding 'in vitro' stimulation of multiple axillary shoot development in some grapevine cultivars for clonal multiplication. Rev. Roum. Biol.-Biol. Veg. 28:115-122.

Sutter, E. and R.W. Langhans. 1979. Epicuticular wax formation on carnation plantlets regenerated from shoot tip culture. J. Amer. Soc. Hort. Sci. 104:493-496.

Swartz, H.J. and J.T. Lindstrom. 1986. Small fruit and grape tissue culture from 1980 to 1985 : Commercialization of the technique, p. 201220. In: R.H. Zimmerman, R.J. Griesbach, F.A. Hammerschlag, and R.H. Lawson (eds.). Tissue culture as a plant production system for horticultural crops. Martinus Nijhoff Publishers, Dordrecht, Netherlands.

Yu, D. and C.P. Meredith. 1986. The influence of explant origin on tissue browning and shoot production in shoot tip cultures of grapevine. J. Amer. Soc. Hort. Sci. 111:972-975.

Zatyko, J.M. and I. Molnar. 1985. Preliminary results on the in vitro mass propagation of grapes from shoot-tip meristem. Fruit Sci. Rpt. 12:8385 . 